\title{
Process capabilities of Micro-EDM and its applications
}

\author{
Kun Liu $\cdot$ Bert Lauwers $\cdot$ Dominiek Reynaerts
}

Received: 13 June 2008 / Accepted: 8 April 2009

(C) Springer-Verlag London Limited 2009

\begin{abstract}
The micro-electrical discharge machining (microEDM) process has proved to be an appropriate nonconventional machining method for manufacturing accurate and complex three-dimensional structural micro-features which are difficult to be produced by conventional processes. However, the miniaturisation of the EDM process requests special requirements on the machining equipment. Pulse generators which can produce small input energy pulses and high precision systems are the two major requirements. In this paper, newly developed technologies regarding these aspects are explored with the aid of a commercial microEDM machine. By examining the pulses, innovative strategies implemented in the pulse generator are studied. Pulse measurements reveal the correlation between the discharge pulses and the machine parameters in order to provide an overview of process capability. Conclusions are applied on machining of a ceramic composite $\mathrm{Si}_{3} \mathrm{~N}_{4}$-TiN and optimised machining settings for different machining conditions are achieved. Accordingly, applications of twoand three-dimensional micro-structures on different types of materials such as a stainless steel micro-compressor and a ceramic miniature gas turbine are demonstrated. By inspecting the machining geometry and surface integrity, process characteristics of micro-EDM are discussed.
\end{abstract}

Keywords Micro-EDM - Ceramic composite . 3D EDM milling

K. Liu $(\triangle) \cdot$ B. Lauwers $\cdot$ D. Reynaerts

Division PMA, Department of Mechanical Engineering,

Katholieke Universiteit Leuven,

Celestijnenlaan 300B,

3001 Heverlee (Leuven), Belgium

e-mail: kun.liu@mech.kuleuven.be

\section{Introduction}

Electrical discharge machining (EDM) is a thermo-electric process which erodes material from the work-piece by a series of discrete sparks between the work-piece and the tool electrode, both submerged in a dielectric fluid. The sparks, occurring at high frequency, continuously and effectively remove the work-piece material by melting and evaporation. The dielectric acts as a deionising medium between two electrodes, and its flow evacuates the resolidified material debris from the gap, assuring optimal conditions for spark generation. The thermal nature of EDM allows machining any electrical conductive material irrespective of its hardness and strength. Generally, EDM allows the shaping of complex structures with high machining accuracy in the order of several micrometres and achievable surface roughness $R_{\mathrm{z}}=0.4 \mu \mathrm{m}$ [1]. During last few decades, this process has found wide applications in many industrial domains, such as mould and die manufacturing and small and burr-free hole drilling. Furthermore, it proves to be a competitive method for ceramic processing because of the abilities to provide accurate, cost-effective and flexible products [2].

As a consequence, the use of EDM for micro-scale manufacturing is inevitable and has been attracting more and more attention in recent years. Promising applications are not only limited to the machining of hard materials for micro-moulds or cutting tools but also the production of difficult-to-make structures such as fuel injection nozzles, spinneret holes for synthetic fibres, electronic and optical devices, micro-mechatronic actuator parts and micro-tools for producing these devices [3]. Moreover, machinable materials are no longer restricted to high-hardness alloys or cemented carbides. More extended applications are the machining of semi-conduct materials such as silicon [4] and 
even insulating ceramics like $\mathrm{Si}_{3} \mathrm{~N}_{4}$ using conductive assisting electrodes [5]. By introducing a conductive secondary phase such as $\mathrm{TiN}, \mathrm{WC}, \mathrm{TiC}_{0.5} \mathrm{~N}_{0.5}$, and $\mathrm{TiB}_{2}$ etc., $\mathrm{Si}_{3} \mathrm{~N}_{4^{-}}, \mathrm{ZrO}_{2^{-}}$and $\mathrm{Al}_{2} \mathrm{O}_{3}$-based advanced engineering ceramics, which have excellent mechanical and physical properties, can also be machined by EDM [1, 6]. In addition, the implementation of high frequency electrical components in pulse generators, development of accurate motion drive devices and the availability of advanced CNC systems allows high precision manufacturing and complex 3D micro-structuring [7-9].

However, the knowledge of micro-EDM of these ceramic composites is still limited, especially on process capability, machining performances and material properties. In this paper, by characterising discharge pulses of the micro-EDM process, machining behaviour of a $\mathrm{Si}_{3} \mathrm{~N}_{4}-\mathrm{TiN}$ ceramic composite, thus, is investigated concerning machining speed and surface quality. First of all, a brief introduction of the micro-EDM configurations as well as an overview of their capabilities is presented. Requirements on micro-scale machining are addressed. Secondly, investigation of machining performances of $\mathrm{Si}_{3} \mathrm{~N}_{4}$-TiN is conducted based on the discharge pulse behaviour in relation with the input electrical parameters; the state-of-the-art strategies applied in pulse generation, thus, are measured, providing essential information to determine the correct parameters combination in order to achieve stable machining conditions. Finally, as application examples, precision machining of stainless steel and ceramic composite into two- and three-dimensional micro-structures such as a microcompressor and a micro-gasturbine as well as the end results are discussed.

\section{Characteristics of micro-EDM}

Similar to macro-EDM, micro-EDM is also classified into several manufacturing configurations by simply scaling down the machining geometries. In general, micro-wire, die-sinking, milling and drilling EDM are the widely recognised machining methods. They can produce a feature size down to a few microns with possible aspect ratio of 100 [3]. In particular, Micro-wire electro-discharge grinding (WEDG), firstly introduced by Masuzawa [10] in 1985, is also regarded as an important micro-EDM configuration (Fig. 1). This process is broadly used for forming very thin rods with high-aspect ratio, which can be used as tool electrodes for micro-EDM drilling or milling. Moreover, it also allows shaping the tools into complex geometries which can be applied directly for fabricating 3D structures [11] and die-sinking. Through on-machine forming of tool electrodes by an integrated WEDG unit, off-centre problems due to spindle rotation can be avoided. An overview

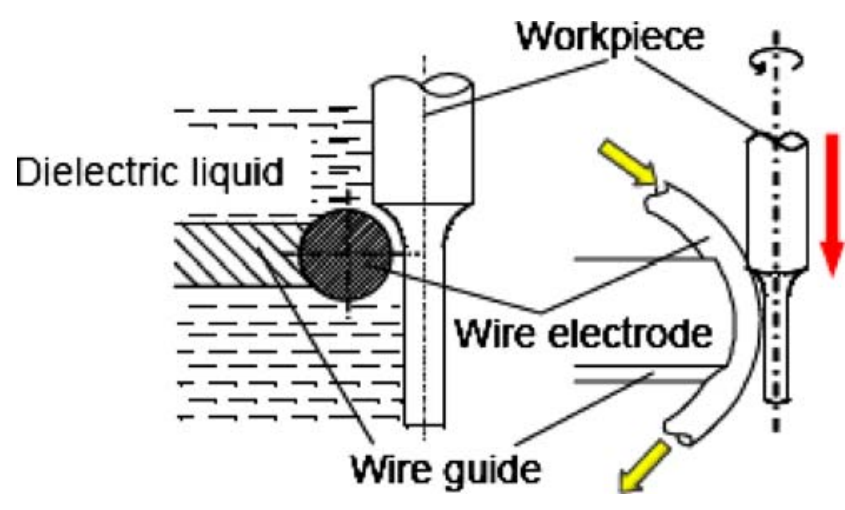

Fig. 1 Wire Electro-discharge grinding (WEDG) [10]

of the capabilities of these machining variants is listed in Table 1.

Generally, in order to satisfy the condition of micromachining, small material unit removal and high precision equipment are required [12]. In the case of micro-EDM, a small unit removal condition commonly means the discharge energy $W_{\mathrm{e}}$ induced in the sparking gap during one pulse must be as low as possible, by which:

$W_{\mathrm{e}}=\int_{0}^{t_{\mathrm{e}}} u_{\mathrm{e}}(t) i_{\mathrm{e}}(t) d t$

with

$W_{\mathrm{e}}$ Discharge energy [J]

$t_{\mathrm{e}} \quad$ pulse duration [s]

$u_{\mathrm{e}}$ Discharge voltage over the sparking gap [V]

$i_{\mathrm{e}} \quad$ Discharge current $[\mathrm{A}]$

During a discharge, gap voltage $u_{\mathrm{e}}$ normally lies in between 10 to $40 \mathrm{~V}$ and is uncontrollable depending on the electrode materials and connecting interfaces. Thus $i_{\mathrm{e}}$ and $t_{\mathrm{e}}$ determine the energy level. To maintain an efficient discharge, $i_{\mathrm{e}}$ has to be sufficiently large; as a consequence, to obtain typically hundreds or tens of $\mathrm{nJ}$ for $W_{\mathrm{e}}, t_{\mathrm{e}}$ has to be reduced significantly to ns range. In conventional EDM where a static iso-energetic pulse generator uses a transistor to switch on/off DC power (Fig. 2a), it is difficult to

Table 1 Overview of micro-EDM capabilities

\begin{tabular}{llrll}
\hline $\begin{array}{l}\text { Micro- } \\
\text { EDM } \\
\text { variant }\end{array}$ & $\begin{array}{l}\text { Geometric } \\
\text { complexity }\end{array}$ & $\begin{array}{l}\text { Min. feature } \\
\text { size }(\mu \mathrm{m})\end{array}$ & $\begin{array}{l}\text { Max. } \\
\text { aspect } \\
\text { ratio }\end{array}$ & $\begin{array}{l}\text { Surface } \\
\text { quality } \\
R_{\mathrm{a}}(\mu \mathrm{m})\end{array}$ \\
\hline WEDM & 3D & 3 & $\sim 100$ & $0.1-0.2$ \\
$\begin{array}{l}\text { Die- } \\
\text { sinking }\end{array}$ & 3D & $\sim 20$ & $\sim 15$ & $0.05-0.3$ \\
Milling & 3D & $\sim 20$ & 10 & $0.2-1$ \\
Drilling & 2D & 5 & $\sim 25$ & $0.05-0.3$ \\
WEDG & 3D & 3 & 30 & 0.5 \\
\hline
\end{tabular}


Fig. 2 Simplified generator schemes for a static pulse generator and $\mathbf{b}$ relaxation pulse generator

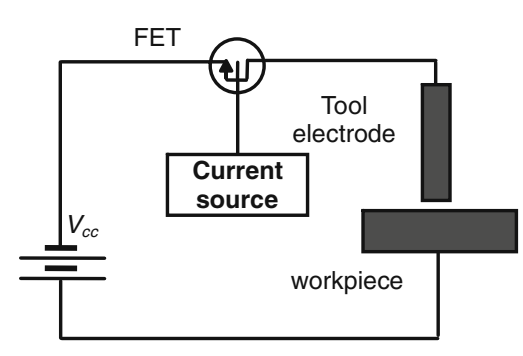

a

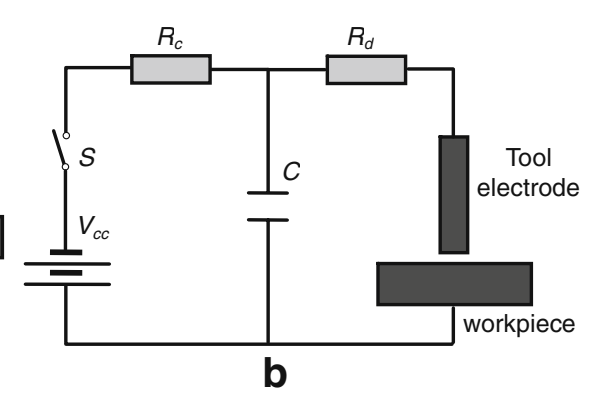

provide short $t_{\mathrm{e}}$ because of the long delay time for the discharge current to diminish to zero after detecting the occurrence of a discharge [1]. In this case, resistancecapacitance (RC)-based generators are widely employed for pulse generation in micro-EDM (Fig. 2b). By using small capacitance (less than $1 \mathrm{nF}$ ) and physically reduce the inductance of the discharge circuit, $t_{\mathrm{e}}$ can be dramatically reduced.

Another important requirement for micro-EDM to obtain high geometry accuracy is accurate tool wear compensation. Variable compensation strategies have been developed in last years, especially for milling EDM. Combinations of on-line discharge pulse sensing and off-line wear prediction are the extensively used method. By inspecting tool length periodically during machining, tool wear can be continuously calculated, and the actual wear compensation factor is adjusted and adapted on the basis of this real-time evaluation [13]. In addition, by integrating the off-line wear prediction factor into CAD/CAM for tool path generation, automated 3D manufacturing becomes feasible, more efficient and accurate.

Last but not least, high precision equipment, the implementation of accurate motion drives and rapid response servo system are required to assure precise movement of the feeding system and stable control of the gap between the electrodes. Several EDM machine tool builders have commercialised these concepts. In the following paragraphs, by characterising the discharge pulses of a relaxation pulse generator, investigation on micro-EDM machining performances of a ceramic composite $\mathrm{Si}_{3} \mathrm{~N}_{4}$-TiN is introduced.

\subsection{Investigation of machining performance on $\mathrm{Si}_{3} \mathrm{~N}_{4}-\mathrm{TiN}$}

\subsubsection{Experimental set-up}

Figure 3 shows the micro-EDM machine used for the experiments: a four-axis SARIX SX-100-HPM (SARIX SA, Switzerland) and its peripherals. The electrical input parameters available on the machine as well as their units are listed in Table 2. Negative polarity is applied through entire experiments, and hydrocarbon oil is used as dielectric.

A schematic view of the set-up for pulse measurement is shown in Fig. 4. As illustrated in this figure, the generator provides the power supply via two cables to the tool electrode and the worktable. The compact construction with short wiring between the generator and the spindle ensures a low stray capacitance and inductance of the entire discharge circuit. By attaching the measurement probes on these two electrical joints respectively and through a floating high voltage differential probe (Tektronix P5205), the voltage signal over the machining gap can be detected and displayed synchronously. The probe for sensing the current (Tektronix A6303) is clamped on one of the cables which is closer to the tool electrode in order to eliminate the influences of inductance between work-piece and ground; the current signal is further amplified by an amplifying system (Tektronix AM503 Current amplifier). Both voltage and current waveforms are read by a high-speed digital oscilloscope (Tektronix TDS 754A, bandwidth $500 \mathrm{MHz}$ and sample rate $2 \mathrm{Gs} / \mathrm{s}$ ).

The $\mathrm{Si}_{3} \mathrm{~N}_{4}$-TiN ceramic composite employed in this research is obtained from a commercial ceramic supplier Saint-Gobain (Kersit $601^{\circledR}$ ). The measured mechanical and physical properties of the composite are listed in Table 3. Tool electrodes applied in the experiment are $\varnothing 0.5 \mathrm{~mm}$ tungsten carbide solid rods rotating at $600 \mathrm{rpm}$.

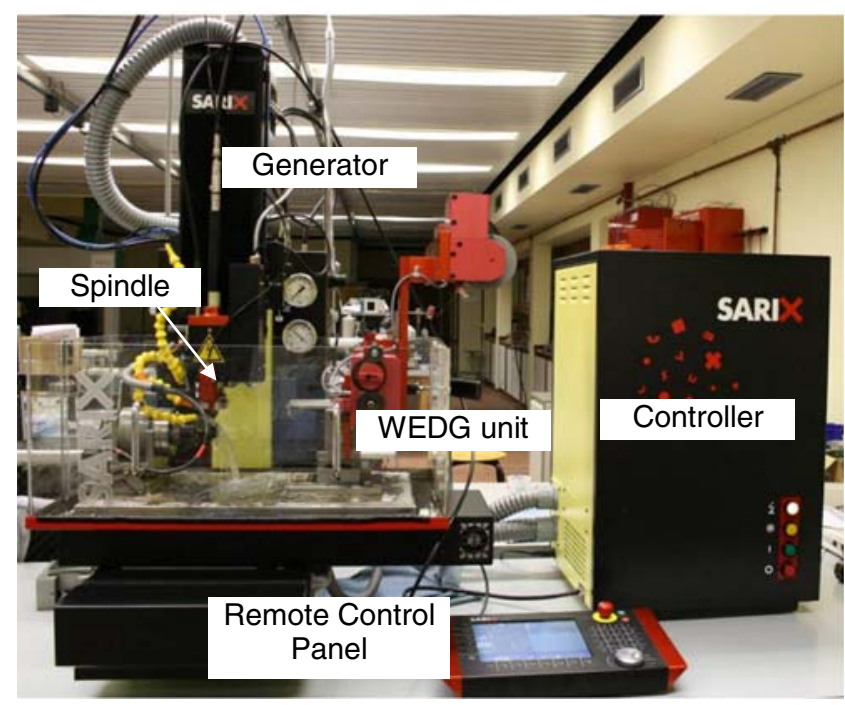

Fig. 3 SARIX SX-100-HPM and peripherals 
Table 2 List of electrical input parameters of the SARIX machine

\begin{tabular}{lllllll}
\hline Parameter & Polarity & Energy & Voltage & Current & Frequency & Width \\
\hline Unit & \pm & (index) & $\mathrm{V}$ & (index) & $\mathrm{kHz}$ & $\mu \mathrm{s}$ \\
Abbreviation & & $E$ & $U$ & $I$ & $F$ & $W$ \\
\hline
\end{tabular}

\subsubsection{Pulse characterisation}

In Fig. 5, collected voltage and current waveforms over the gap during machining are displayed. It shows the gap status for a time period of $50 \mu \mathrm{s}$ with three consecutive normal discharge pulses. At the beginning of a spark, the open gap voltage $U_{\mathrm{o}}$ between the electrodes is maintained at $100 \mathrm{~V}$ until the dielectric breaks down and the discharge current $i_{\mathrm{e}}$ (maximum value $\sim 4 \mathrm{~A}$ ) flows through the gap for a discharge duration $t_{\mathrm{e}}$. By using higher acquisition rate of the oscilloscope, this duration is accurately measured as $380 \mathrm{~ns}$. After a time interval $t_{\mathrm{o}}$ of $5 \mu \mathrm{s}$, the capacitor in the $R C$ circuit starts to be recharged. However, it is not directly charged to the open gap voltage $U_{\mathrm{o}}$ like a normal $R C$ generator. After a duration $t_{\mathrm{c} 1}$, an intermediate voltage $U^{\prime}$ around $30 \mathrm{~V}$ is achieved. This voltage is not able to break down the dielectric and initiate the spark. After a delay period $t_{\mathrm{d} 1}$, the gap voltage reaches $U_{\mathrm{o}}$ during a second charging period $t_{\mathrm{c} 2}$. After an ignition delay $t_{\mathrm{d}}$, a discharge occurs and the energy stored in the $R C$ circuit is released. At this moment, a whole charge and discharge pulse cycle has been accomplished and the pulse cycle time is characterised by $t_{\mathrm{p}}$.

Apparently, with the exception of parameter $U$, there is no obvious relation between the input parameters $I$ and $W$ and the actual discharge pulses in the way of peak current $i_{\mathrm{e}}$, cycle time $t_{\mathrm{p}}$ and duration $t_{\mathrm{e}}$. However, it is noticed that the charge cycle $\left(t_{\mathrm{c} 1}+t_{\mathrm{d} 1}\right)$ is equal to the reciprocal of parameter $F$.

By changing parameter $E$, similar patterns of voltage and current waveforms are examined (Fig. 6). However, the average maximum discharge current shows dramatic differences even if all the other parameters are kept almost the same. Meanwhile, the discharge duration is reduced from 800 to $80 \mathrm{~ns}$, together with a dramatic reduction of average peak current. Apparently, the discharge energy level, which is expressed by means of an index number grouped in series, separates the layouts of the generator and determines

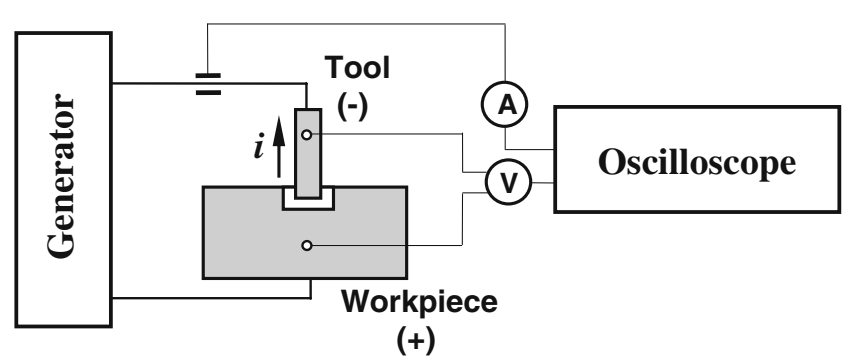

Fig. 4 Schematic view of the set-up for pulse measurement the amount of energy stored in the $R C$ circuit. Because of the different configurations of generator, a negative voltage is observed during the discharge when applying $E 110$; yet, this phenomenon is not observed when applying E 206 and E 15 .

In Fig. 7, variant voltage and current waveforms are obtained by increasing the input parameters $U$ and $I$, respectively. Other electrical parameters are kept the same as shown in Fig. 5. The discharge current duration shows little change (350-400 ns) in both variations. In Fig. 7a, the input parameter voltage changes to $200 \mathrm{~V}$. As a result, $U_{\mathrm{o}}$ increases to the corresponding value but three intermediate voltage steps are involved comparing to one step in Fig. 5. The pulse cycle time $t_{\mathrm{p}}$ is increased accordingly, as well as the maximum discharge current. Consequently, the energy input for each pulse is raised. In contrary, the increase of input parameter $I$ (Fig. 7b) does not bring any variation on $i_{\mathrm{e}}$. In this condition, the voltage is directly charged to $U_{\mathrm{o}}$ without any intermediate step. Compared to Fig. 5, it results in a reduced cycle time and the efficiency of the discharge is increased. Nevertheless, more abnormal discharges are observed in general because of less relaxing time to recover the strength of the gap.

Waveform comparisons by varying the last two electrical parameters $F$ and $W$ are also illustrated in Fig. 8. Other electrical parameters are kept the same as shown in Fig. 5. According to the measurement, the variation of these two parameters does not provide any change in the discharge pulse duration $t_{\mathrm{e}}$; a slight difference in maximum discharge current $i_{\mathrm{e}}$ is examined. As mentioned before, with the decrease of $F$ (Fig. 8a), the cycle time for each recharge is correspondingly prolonged. As can be seen on Fig. 8b, the decrease of $W$ leads to an increased number of charging

Table 3 Mechanical and physical properties of $\mathrm{Si}_{3} \mathrm{~N}_{4}$-TiN ceramic composite

\begin{tabular}{|c|c|c|}
\hline \multicolumn{2}{|l|}{ Supplier } & Saint-Gobain \\
\hline \multicolumn{2}{|l|}{ Grade } & Kersit 601 \\
\hline \multirow[t]{2}{*}{ Chemical composition } & $\mathrm{Si}_{3} \mathrm{~N}_{4}$ & 64 vol. \% \\
\hline & TiN & 36 vol. $\%$ \\
\hline \multicolumn{2}{|l|}{ Density $\left(\mathrm{g} / \mathrm{cm}^{3}\right)$} & 3.97 \\
\hline \multicolumn{2}{|c|}{ Hardness $\mathrm{HV}_{10}\left(\mathrm{~kg} / \mathrm{mm}^{2}\right)$} & $1508 \pm 33$ \\
\hline \multicolumn{2}{|c|}{ 3-point bending strength $(\mathrm{MPa})$} & $979 \pm 120$ \\
\hline \multicolumn{2}{|c|}{ Young's modulus (GPa) } & $333 \pm 3$ \\
\hline \multicolumn{2}{|c|}{ Electrical Resistivity $\left(10^{-7} \Omega \mathrm{m}\right)$} & 160 \\
\hline \multicolumn{2}{|c|}{ Thermal conductivity $20^{\circ} \mathrm{C}\left(\mathrm{Wm}^{-1} \mathrm{~K}^{-1}\right)$} & 28 \\
\hline
\end{tabular}




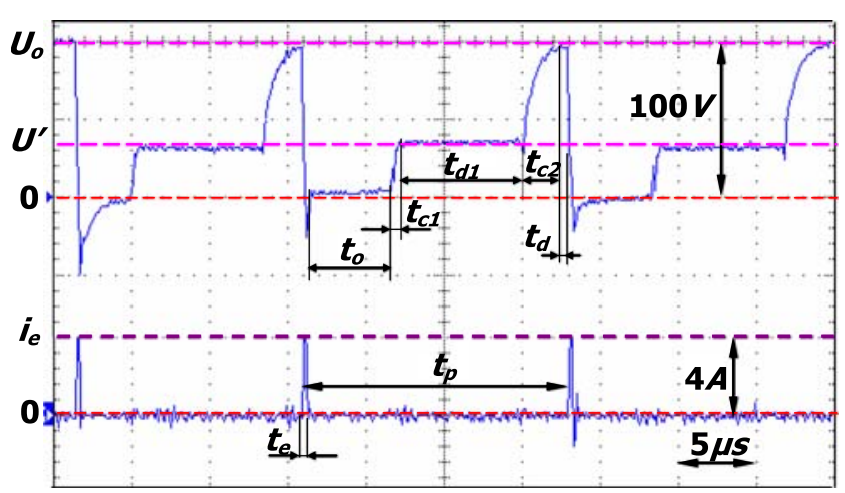

Fig. 5 Measured voltage and current waveforms over the discharge gap; $E=110, U=100 \mathrm{~V}, I=80, F=120 \mathrm{kHz}, W=3.0 \mu \mathrm{s}$

steps though the time intervals in between are kept constant comparing to the waveform in Fig. 5. In both cases, the discharge cycle time is extended.

As a conclusion, this advanced $R C$-based generator is able to generate very short discharge pulses in favour of providing small unit removal as mentioned in the first section of this chapter. At the limits of the machining parameters, extreme short pulse duration of $50 \mathrm{~ns}$ and low discharge current of $0.25 \mathrm{~A}$ are observed. Taking discharge voltage $u_{\mathrm{e}} \sim 20 \mathrm{~V}$, discharge energy around $125 \mathrm{~nJ}$, thus, can be obtained. The reason for the generator builders to apply this multiple-step $R C$ charging strategy is highly likely to have more controllability and uniformity of the discharging process, the lack of which has been proved to be the disadvantage for conventional $R C$ generators [14]. Furthermore, comparing to consecutive pulses generated by a conventional $R C$ generator, more time interval is allowed for the dielectric to recover its strength and the possibilities of abnormal machining can be reduced. Still, there is no explicit explanation on the correlation between some of the electrical parameters with the discharge pulses which could determine the charge behaviour of the capacitor in the $R C$ circuit. So far, further pulse analysis and evaluation are still under investigation.

\subsubsection{Machining performances and strategy development}

Based on the discharge pulse characterisation performed in previous section, more understanding of the machine parameters is obtained. Accordingly, process investigations on the machining of $\mathrm{Si}_{3} \mathrm{~N}_{4}$-TiN ceramic composite become more straightforward. Since the energy difference is discrete and mainly determined by parameter $E$, three machining regimes are investigated: roughing, semifinishing and finishing, respectively. For the roughing regime, maximum material removal regardless of tool wear and surface quality is preferred; for semi-finishing and finishing regime, low tool wear to attain a shape consistency and geometrical accuracy, as well as a satisfactory surface roughness, is required. By varying other electrical parameters, a stable machining condition is achieved for each regime. It allows a sufficient period of the pulse interval for recovering the strength of the gap, while keeping up a maximum machining efficiency; in the meantime, no violent arcing behaviour, light flashes and presence of short circuits or arc discharges are observed on the oscilloscope.

Machining performances in the form of material removal rate (MRR), tool wear ratio, surface roughness $\left(R_{\mathrm{a}}\right)$ and the sparking gap for each regime are listed in Table 4. The measured open gap voltage $U_{\mathrm{o}}(\mathrm{V})$, average peak current $i_{\mathrm{e}}(\mathrm{A})$, average pulse duration $t_{\mathrm{e}}(\mu \mathrm{s})$ and pulse interval $t_{\mathrm{o}}(\mu \mathrm{s})$ are also listed in the table correspondingly.

As can be seen in the table, micro-EDM machining properties of this ceramic composite is following the same trend as machining of steel: higher discharge energy, higher machining speed, higher surface roughness and less the tool electrode wear. The material removal rate is high comparing with machining stainless steel, and extremely low tool wear is revealed. However, relatively high surface roughness is obtained even at the finishing regime where the parameters are nearly operated at the limit of the machine settings. Further research [15] explains this phenomenon according to the examination of the surface microstructure;
Fig. 6 Comparisons of voltage and current waveforms with varied input parameter $E$ : a $E=206, U=100 \mathrm{~V}, I=30$, $F=100 \mathrm{kHz}, W=3.0 \mu \mathrm{s}$; b $E=15, U=70 \mathrm{~V}, I=30$, $F=120 \mathrm{kHz}, W=5.0 \mu \mathrm{s}$

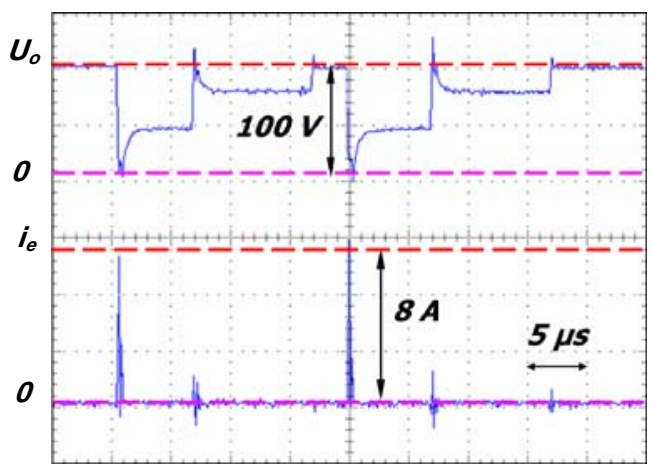

a

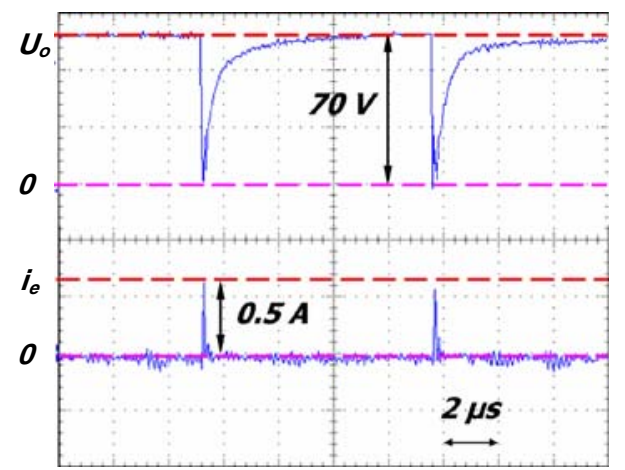

b 
Fig. 7 Comparisons of voltage and current waveforms with varied input parameters: a $U=200 \mathrm{~V} ; \mathbf{b} I=100$. Other input parameters are the same as in Fig. 4

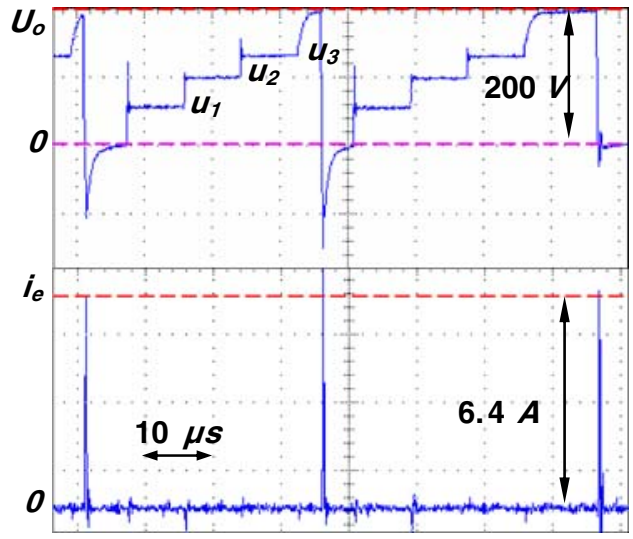

a

Fig. 8 Comparisons of voltage and current waveforms with varied input parameters: a $F=60 \mathrm{kHz} ; \mathbf{b} W=0.1 \mu \mathrm{s}$. Other input parameters are the same as in Fig. 4

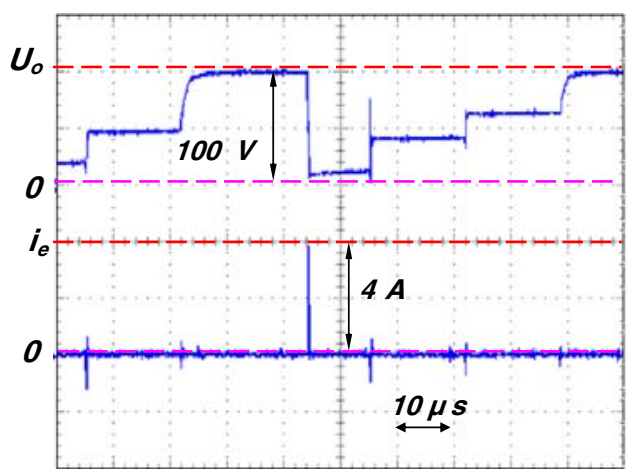

a

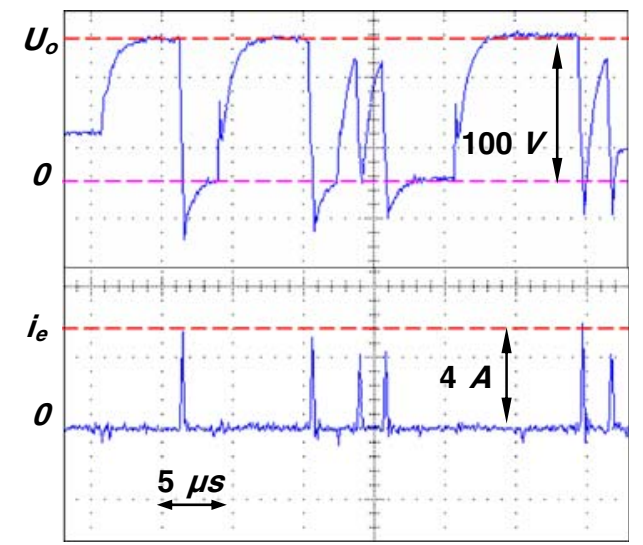

b

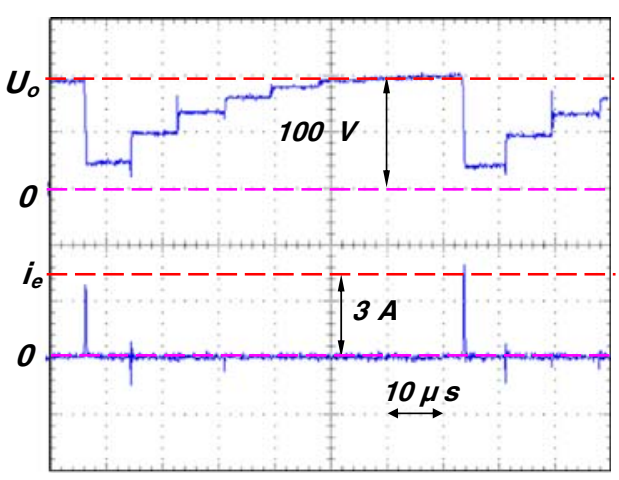

b

Table 4 Micro-EDM milling of $\mathrm{Si}_{3} \mathrm{~N}_{4}$-TiN machining parameters and properties with WC tool electrode

\begin{tabular}{lccc}
\hline Regime & Roughing & Semi-finishing & Finishing \\
\hline Electrical parameter & & & \\
$\quad U_{\mathrm{o}}(\mathrm{V})$ & -150 & -100 & -70 \\
$i_{\mathrm{e}}(\mathrm{A})$ & 16.5 & 10 & 0.6 \\
$t_{\mathrm{e}}(\mu \mathrm{s})$ & 1.30 & 0.87 & 0.05 \\
$t_{\mathrm{o}}(\mu \mathrm{s})$ & 10 & 6 & 9 \\
Machining properties & & & \\
MRR $\left(\mathrm{mm}^{3} /\right.$ min) & 0.364 & 0.121 & 0.002 \\
TWR $(\%)$ & 1.82 & 7.55 & 12.71 \\
$R_{\mathrm{a}}(\mu \mathrm{m})$ & 2.45 & 1.45 & 0.62 \\
Gap $(\mu \mathrm{m})$ & 15 & 10 & 5 \\
\hline
\end{tabular}


Fig. 9 Micro-EDM hole drilling on ceramic composite $\mathrm{Si}_{3} \mathrm{~N}_{4}$-TiN with aspect ratio of 20

Fig. 10 A micro-compressor on a $\varnothing 1 \mathrm{~mm}$ cylinder: top and detail views
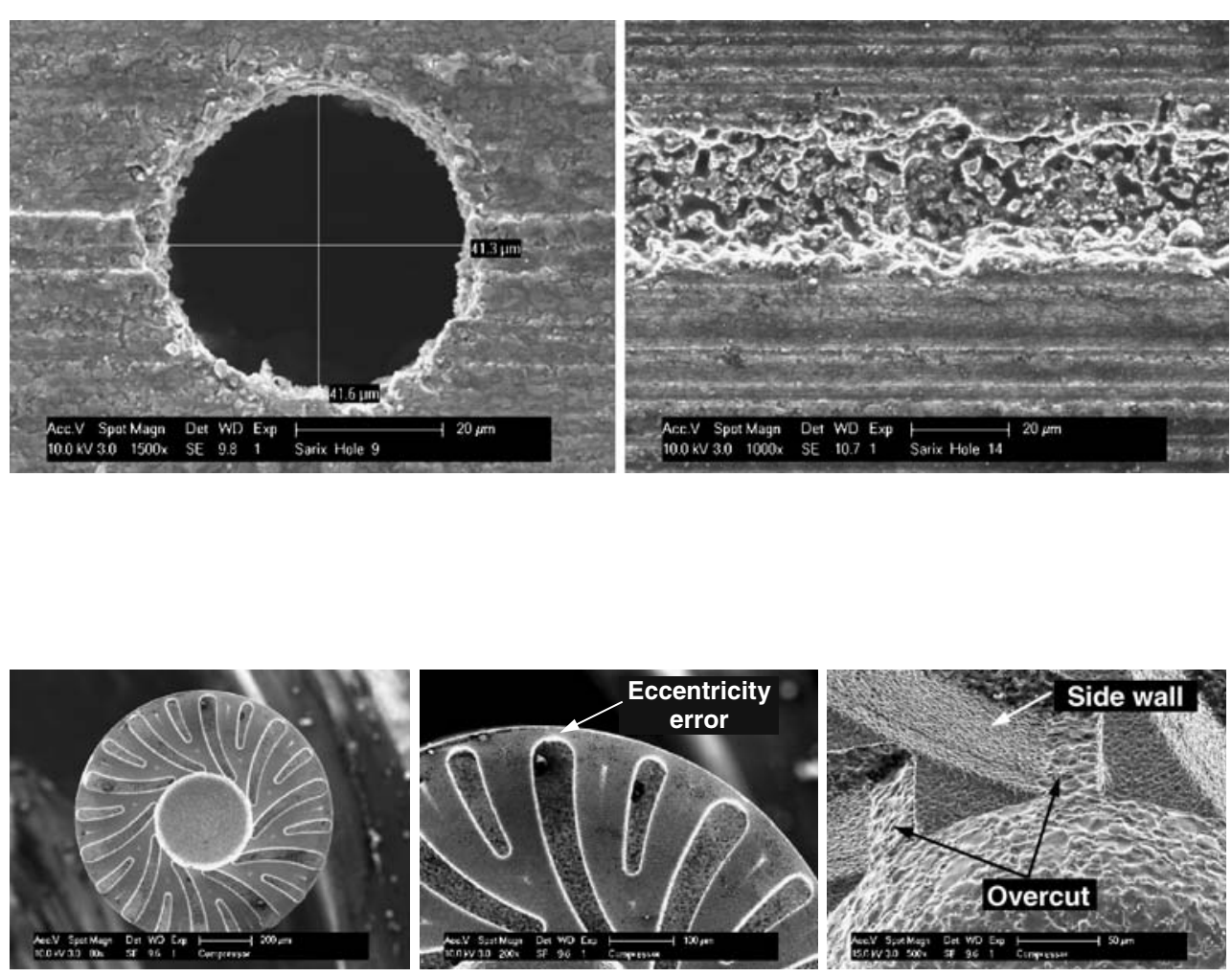

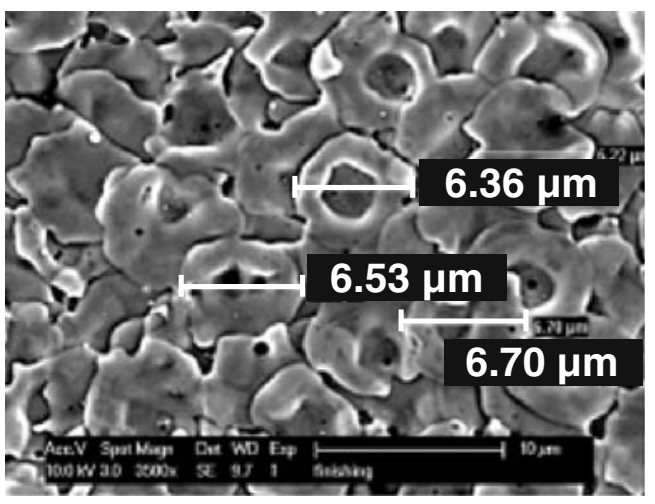

Fig. 11 Discharge crater size of micro-EDM milling processes

Fig. 12 Close views of the Micro-EDM milling process and a finished turbine impeller
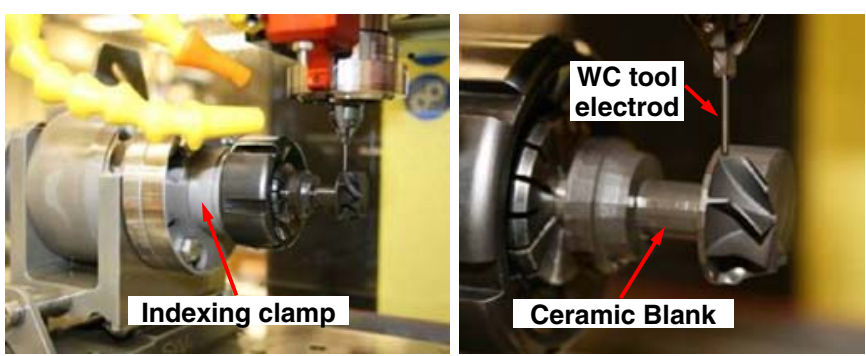
chemical reactions which lead to decomposition and oxidation of $\mathrm{Si}_{3} \mathrm{~N}_{4}$ and TiN during the EDM process as main material removal mechanisms are proposed. This intrinsic property limits the surface quality which can be achieved but in another way helps the material removal speed on this ceramic composite.

\subsection{Micro-machining applications}

In the previous section, low discharge pulse energy generation as a requirement for realising micro-machining has been described. In this section, micro-EDM results obtained with precision equipment, represented by the machining examples on both traditional and novel materials, i.e. stainless steel and $\mathrm{Si}_{3} \mathrm{~N}_{4}-\mathrm{TiN}$ ceramic composite will be presented. With the examined results, micromachining characteristics are discussed.

This machine uses both micro-EDM milling and drilling configurations with an integrated WEDG unit. The specially designed spindle and clamping head allow the use of thin solid or tubular electrodes with diameters ranging from 0.04 to $1.0 \mathrm{~mm}$ combined with external or internal dielectric flushing. The electrodes, varying in different sizes and materials, are commercially available. They can also be shaped in situ by the WEDG unit. This allows obtaining micro-tools down to a diameter of $8 \mu \mathrm{m}$ with almost zero run-out. The machine applies a layer-by-layer milling strategy with very small layer thickness, which assures the frontal shape intactness of the electrode and relatively exact anticipated tool wear compensation value. During the process, a reference point nearby the working area is defined, tool length is, thus, examined periodically at this point; anticipated tool wear compensation value is recalculated according to the measurement results and adapted into further machining. Furthermore, the electrode feeding system can automatically extend the active tool length if the machine detects a tool shortage. Thanks to the advanced motion drive system, a minimum machining layer of $0.1 \mu \mathrm{m}$ can be set. Therefore, accurate manufacturing of complex shapes can be well achieved. A special CAM module developed by ESPRIT for SARIX in combination with the WEDG unit simplifies the programming and provides possibilities of automation.

As mentioned in the first chapter, one of the widest applications for micro-EDM is burr-free hole drilling. In Fig. 9, a micro-hole on ceramic composite $\mathrm{Si}_{3} \mathrm{~N}_{4}$-TiN with diameter around $\varnothing 0.041 \mathrm{~mm}$ and an aspect ratio of 20 is shown. It is machined by a $\varnothing 0.02 \mathrm{~mm}$ WEDGed tungsten carbide tool using the semi-finishing regime. However, it suffers from poor surface quality as can be seen in the cross section view (Fig. 9) because of intrinsic EDM material removal mechanisms mentioned in previous section (Sec- tion 2.1.3). As a result, limited shape accuracy can be attained.

The second application example presented here is a micro-compressor (Fig. 10). It is a two-and-a-half dimensional structure, machined on the tip of a 1-mm diameter cylinder. Materials used for electrode and work-piece are tungsten carbide and stainless steel, respectively. The centre hole with diameter $0.3 \mathrm{~mm}$ is micro-EDM drilled directly with a purchased electrode. The blades are micro-EDM milled with the same tool after it was reduced to a diameter of $40 \mu \mathrm{m}$ by WEDG. The incremental depth for each micro-EDM milling layer is $0.5 \mu \mathrm{m}$. All the blades show good consistency, and the examined shape accuracy is less than $1 \mu \mathrm{m}$. Furthermore, no taper angle and obvious path mark on the side wall of the blades is observed.

However, the achieved geometry still reveals a problem. An eccentricity error of about $20 \mu \mathrm{m}$ is measured (Fig. 10). This could be introduced by the centring procedure of the cylinder. Overcut of the blades around the centre hole could be due to the lack of accurate information on the sparking gap size with the corresponding machining settings.

Since it is not possible to use a tactile roughness measuring system and there is no optical profilometer available, the surface roughness of machined blades can only be estimated empirically. The examined crater size on micro-EDM milled surfaces (Fig. 11) is about $6.5 \mu \mathrm{m}$ in average. The relationship between the single-shot discharge cavity and surface roughness $R_{\max }$ is estimated according to Eq. 2 as mentioned in [16]:

$R_{\max }=2 h_{1}+h_{2} \quad d=(10 \sim 20) h_{1}$

where $d$ and $h_{1}$ are the diameter and depth of the single-shot discharge cavity, respectively; $h_{2}$ is the protrusion height around the discharge cavity. Take an experiential value $h_{2}=$ $0.2 \mu \mathrm{m}$, the evenly spread craters for the micro-EDM milling process should give an $R_{\max }$ around $0.85 \mu \mathrm{m}$. An average surface roughness $R_{\mathrm{a}}$ of about $0.08 \mu \mathrm{m}$ is estimated (take $R_{\text {max }} \approx 10 \times R_{\mathrm{a}}$ ).

Another application example is micro-EDM milling of $\mathrm{Si}_{3} \mathrm{~N}_{4}$-TiN ceramic composite into a miniature threedimensional gas turbine impeller which serves as a key component for a micro power generation system [17]. A close view of the manufacturing process is illustrated in Fig. 12. The milling of each cavity starts with a $\varnothing 1.0 \mathrm{~mm}$ WC tool for pocketing using the roughing regime to remove the bulk of the material, then followed by a $\varnothing$ $0.7 \mathrm{~mm}$ tool for wall finishing using the semi-finishing regime. Due to the extremely low machining speed of the finishing regime, only two steps are performed. The same layer-by-layer machining strategy is applied and the layer thickness for pocketing and wall finishing are 8 and $3 \mu \mathrm{m}$, respectively. The shape and geometrical accuracy of the 
cavity is measured on a Coordinate Measuring Machine (Mitutoyo FN 905). All machined surfaces (pressure, suction and hub surfaces) show good consistency comparing with the original CAD model. However, even with rather high MRR, the total machining time for one cavity takes around $20 \mathrm{~h}$.

\section{Conclusion}

The requirements for the micro-EDM process are presented and discussed. According to the studies of pulse generation on a commercial micro-EDM machine, advanced strategies applied by the machine builders have been revealed. The ability of producing ultra-short discharge pulse duration in the range of $50 \mathrm{~ns}$ and low discharge current of $0.25 \mathrm{~A}$, guarantees a small energy input of each discharge and assures a small unit material removal. However, there still remains a lack of explicit correlation between some machining parameters and generated pulses. High feature accuracy less than $1 \mu \mathrm{m}$ on a 2.5 dimensional stainless steel application example is achieved. The machining of exotic material such as $\mathrm{Si}_{3} \mathrm{~N}_{4^{-}}$ TiN ceramic composite into a complex three dimensional structure gives also excellent result in shape accuracy.

Acknowledgement This research is sponsored by the Institute for the Promotion of Innovation by Science and Technology in Flanders, Belgium, project SBO 030288, and by the Belgian programme on Interuniversity Poles of Attraction (IAP5/06: AMS). This work is also carried out within the framework of the EC Network of Excellence "Multi-Material Micro Manufacture: Technologies and Applications $(4 \mathrm{M}) "$.

\section{References}

1. Kunieda M, Lauwers B, Rajurkar K, Schumacher BM (2005) Advancing EDM through fundamental insight into the process. CIRP Ann 54(2):599-622. doi:10.1016/S0007-8506(07)60020-1

2. Ho KH, Newman ST (2003) State of the art electrical discharge machining (EDM). Int $\mathrm{J}$ Mach Tools Manuf 43:1287-1300. doi:10.1016/S0890-6955(03)00162-7

3. Rajurkar KP, Levy G, Malshe A, Sundaram MM, McGeough J, Hu X, Resnick T, DeSilva A (2006) Micro and nano machining by electrophysical and chemical processes. CIRP Ann 55(2):643666. doi:10.1016/j.cirp. 2006.10.002

4. Song X, Meeusen W, Reynaerts D, Van Brussel H (2000) Experimental study of micro-EDM machining performances on silicon wafer. Proceedings of SPIE's 2000 Symposium on Micromachining and Microfabrication, Santa Clara, USA, pp 331-339

5. Muttamara A, Fukuzawa Y, Mohri N, Tani Y (2003) Probability of precision micro-machining of insulating $\mathrm{Si}_{3} \mathrm{~N}_{4}$ ceramics by EDM. J Mater Process Technol 140:243-247. doi:10.1016/S09240136(03)00745-3

6. Lauwers B, Kruth JP, Liu W, Schacht B, Bleys P (2004) Investigation of the material removal mechanisms in EDM of composite ceramic materials. J Mater Process Technol 149:347352. doi:10.1016/j.jmatprotec.2004.02.013

7. Pham DT, Dimov SS, Bigot S, Ivanov A, Popov K (2004) MicroEDM-recent developments and research issues. J Mater Process Technol 149:50-57. doi:10.1016/j.jmatprotec.2004.02.008

8. Fleischer J, Masuzawa T, Schmidt J, Knoll M (2004) New applications for micro-EDM. J Mater Process Technol 149:246249. doi:10.1016/j.jmatprotec.2004.02.012

9. Reynaerts D, Van Brussel H, Meeusen W, Driesen W, Dierickx V (2001) Micro-Electro Discharge Machining: review and application. Proactive Strategies of Efficient Production Technology, pp 107-122

10. Masuzawa T, Fujino M, Kobayashi K, Suzuki T, Kinoshita N (1985) Wire electro-discharge grinding for micro-machining. CIRP Ann 34(1):431-434. doi:10.1016/S0007-8506(07)61805-8

11. Reynaerts D, Meeusen W, Van Brussel H (1998) Machining of three-dimensional microstructures in silicon by electro-discharge machining. Sens Actuators A Phys 67:159-165. doi:10.1016/ S0924-4247(97)01724-X

12. Masuzawa T (2001) Micro-EDM. Proceedings of 13th International Symposium on Electromachining (ISEM XIII). Bilbao, Spain, pp 3-19

13. Bleys P, Kruth JP, Lauwers B, Zryd A, Delpretti R, Tricarico C (2002) Real-time tool wear compensation in Milling EDM. CIRP Ann 51(1):157-160. doi:10.1016/S0007-8506(07)61489-9

14. Han F, Wachi S, Kunieda M (2004) Improvement of machining characteristics of micro-EDM using transistor type isopulse generator and servo feed control. Precis Eng 28:378-385. doi:10.1016/j.precisioneng.2003.11.005

15. Liu K, Ferraris E, Peirs J, Lauwers B, Reynaerts D (2008) MicroEDM process investigation of $\mathrm{Si}_{3} \mathrm{~N}_{4}$-TiN ceramic composites for the development of micro fuel-based power units. Int J Manuf Res 3:27-47. doi:10.1504/IJMR.2008.016451

16. Liao YS, Chen ST, Lin CS (2005) Development of a high precision tabletop versatile $\mathrm{CNC}$ wire-EDM for making intricate micro parts. J Micromech Microeng 15:245-253. doi:10.1088/ 0960-1317/15/2/001

17. Peirs J et al (2007) Micropower generation with microgasturbines: a challenge. Proc IMechE, Part C. J Mech Eng Sci 221:489-500 